\title{
Type 2 diabetes is an independent predictor of weight loss in Tier 3 Weight Assessment and Management Services
}

\author{
ALIYA SYAHRENI PRIHARTADI*, GIOVANNA IMPELLIZIERE LICASTRO* , HARSHAL DESHMUKH, \\ SUFYAN BENAMER, KYAW LINN, NAJEEB SHAH, THOZHUKAT SATHYAPALAN, KAMRUDEEN MOHAMMED
}

\begin{abstract}
Introduction: A specialist weight management service provides an effective treatment option for severe obesity; however, there are limited data exploring the baseline predictors of response and effect on $\mathrm{HbA}_{1 c}$ following engagement with the service.

Methods: We used prospective data from the regional weight management services within the Hull University Teaching Hospitals NHS Trust Tier 3 Obesity Programme. Data were available for $\mathbf{2 4 9}$ patients referred to the service. T-tests were used for univariate baseline characteristics of those with and without $5 \%$ weight loss after engagement with the service. Logistic regression analysis was used to identify independent predictors of weight loss at 12 months. Results: A total of 309 patients were referred to the Tier 3 adult weight management service, of which 249 (80.6\%) participated in the programme and had at least one follow-up. The median age of the study population was $\mathbf{4 6}$ years (range 36-55) and consisted of $66 \%$ females with a median baseline body mass index of $44 \mathrm{~kg} / \mathrm{m}^{2}$ (range $42-45$ ). The prevalence of type 2 diabetes was $31 \%$, hypertension was $35 \%$, gastrooesophageal reflux disease was $34 \%$ and osteoarthritis was $29 \%$. The median baseline weight on enrolment in the programme was $126 \mathrm{~kg}$ (range 115-138). During the followup period of 1 year, the median weight fell to $120.5 \mathrm{~kg}$ at 3 months, $119.6 \mathrm{~kg}$ at 6 months, $117.7 \mathrm{~kg}$ at 9 months and $117.5 \mathrm{~kg}$ at 12 months. The median $\mathrm{HbA}_{1 \mathrm{c}}$ fell from a baseline of $60.25 \mathrm{mmol} / \mathrm{mol}$ to $54.4 \mathrm{mmol} / \mathrm{mol}$ during the follow-up period. Sixty-four patients had a baseline $\mathrm{HbA}_{1 \mathrm{c}}$ of $>53$ $\mathrm{mmol} / \mathrm{mol}\left(7 \% \mathrm{HbA}_{1 \mathrm{c}}\right)$, which fell to $<53 \mathrm{mmol} / \mathrm{mol}$ in $21 \%$ of patients during the follow-up period. In the logistic regression model, higher age (OR 1.05, $\mathrm{p}=0.0001)$, type 2
\end{abstract}

\footnotetext{
*Joint first authors

Hull University Teaching Hospitals NHS Trust, Hull, UK
}

Address for correspondence: Dr Kamrudeen Mohammed Consultant Diabetologist and Endocrinologist, Hull University Teaching Hospitals NHS Trust, Brocklehurst Building, Anlaby Road, Hull HU3 2JZ, UK E-mail: Kamrudeen.Mohammed@hey.nhs.uk

https://doi.org/10.15277/bjd.2020.263 diabetes (OR 2.54, $p=0.002)$ and dyslipidaemia (OR 2.21, $p=0.03$ ) were independently associated with more than $5 \%$ weight loss at 12 months follow-up.

Conclusion: Engagement with Tier 3 adult weight management is associated with significant weight loss and improvement in glycaemic control in a large proportion of patients at one year. Higher age, diabetes and dyslipidaemia at baseline are independent predictors of weight loss on the Tier 3 weight management service.

Br J Diabetes 2020;20:117-121

Key words: Tier 3 weight management, weightwise, BMI, obesity, diabetes, $\mathrm{HbA}_{1 c}$, predictors of weight loss

\section{Introduction}

Obesity has become an increasing global problem, and its prevalence is reaching pandemic proportions. It is classified as a body mass index (BMI) of $\geq 30 \mathrm{~kg} / \mathrm{m}^{2}$, with morbidly obese defined as a BMI of $\geq 40 \mathrm{~kg} / \mathrm{m}^{2}$. In the UK, $29 \%$ of the adult population is obese and $4 \%$ are morbidly obese, with the proportion of obesity increasing with age among both sexes.

Oxidative stress due to obesity is associated with metabolic syndrome, hypertension, diabetes, dyslipidaemia, atherosclerosis and cancer. ${ }^{2-5}$ It is also related to fatty liver disease, gallstones, gastro-oesophageal reflux disease (GORD), obstructive sleep apnoea and psychiatric disease. ${ }^{2}$ During the ongoing COVID-19 pandemic, obesity has emerged as one of the most critical risk factors for increased morbidity and mortality. 5,6 Many of these conditions associated with obesity can be reversed with weight loss. ${ }^{7-12}$ For instance, a recent study in patients with type 2 diabetes (Diabetes Remission Clinical Trial (DiRECT)) determined that a weight loss of more than $10 \%$ can cause remission of diabetes in two-thirds of patients. ${ }^{13,14}$ Weight loss has also been shown to have a beneficial effect on blood pressure, renal function and to reduce the risk of various cancers. ${ }^{3}$

The UK National Health Service (NHS) manages obesity using a tier-based system. Tiers 1 and 2 are aimed at individuals who are overweight, and services are provided by community-based encouragement of a healthier lifestyle through diet and exercise. Tier 1 focuses on brief health advice, which includes public health and national campaigns. Tier 2 involves health and weight 
management services, which patients can self-refer to or be referred via their GP. The Tier 3 Weight Assessment and Management Service (T3WAMS) ${ }^{11,12}$ is aimed at individuals who are obese, have other complex medical needs and have not responded to previous tier interventions. It involves specialist assessment and multidisciplinary management with at least a bariatric physician or endocrinologist, a dietician, a specialist nurse, a clinical psychologist and access to physical therapy. Tier 4 management ${ }^{13}$ involves multidisciplinary team (MDT) support and bariatric surgery, and is offered to adults who have a BMl of $\geq 40 \mathrm{~kg} / \mathrm{m}^{2}$, or $\geq 35 \mathrm{~kg} / \mathrm{m}^{2}$ with comorbidities who have gone through or will go through the Tier 3 management, or those with a BMI of $\geq 50 \mathrm{~kg} / \mathrm{m}^{2} .5,9,11,12$

The evidence of effectiveness behind T3WAMS is growing, and with it is the need for more descriptive data regarding its impact on different patient populations for a more individualised patient-focused service. ${ }^{11,14}$ One observational study ${ }^{12}$ reported patient characteristics that were associated with higher patient engagement, which included older age, diagnosis with obstructive sleep apnoea and higher BMl at the time of referral. This study also established a significant association between the completion rate of T3WAMS and weight loss. Although completion rates have repeatedly been associated with higher weight loss and health risk reduction, the evidence describing the independent relationship between baseline clinical characteristics and weight reduction is scarce. Given the ever increasing demand for T3WAMS and significant pressures on the service, it is crucial to identify the patients who are most likely to benefit from the T3WAMS. The objective of the study is therefore to examine the effect of the T3WAMS on weight loss and identify the baseline clinical characteristics associated with weight loss in our specialised weight management programme.

\section{Methods}

This prospective study was performed using longitudinal data from the regional weight management Tier 3 services within the Hull University Teaching Hospitals NHS Trust. Follow-up on the change in longitudinal weight was done over one year. The area encompassed by our Tier 3 service has been deemed the fourth local authority district with the most substantial proportion of high deprived neighbourhoods in England. Kingston upon Hull ranked in the top 10 in every measure of deprivation according to the 2019 report of the English Indices of Deprivation. The service's catchment area also includes North and North East Lincolnshire, which also has high levels of deprivation.

The T3WAMS began to receive referrals in May 2015 from both North Lincolnshire CCG and North East Lincolnshire CCG. The bariatric specialist nurse received referrals via post or internal email and triaged the referrals to decide if patients were acceptable to be appointed to the T3WAMS according to the previously mentioned criteria. If a patient met the criteria, they would be sent a contract from the service, offering them a place in the weight management programme. Once the patient has accepted a place, the Tier 3 MDT coordinator books an initial multidisciplinary clinic appointment which includes an endocrinologist/bariatric physician, bariatric specialist nurse, psychological therapist, highly specialist dietician (bariatric) and the Tier 3 MDT coordinator. An individual plan is generated for each patient. The patients can go through a dietetic pathway which includes one-to-one sessions with specialist dieticians with an appointment at 3, 6, 9 and 12 months. The patients get bariatric blood screening, onward referrals for sleep studies, exercise on referral, etc. These patients also get multiple follow-up sessions if counselling/treatment, cognitive behavioural therapy, etc is required at 3- and 6-month intervals.

Initially, 309 patients were referred to the T3WAMS, of which data were available for 249 who participated in the programme and had at least one follow-up. The population included adult patients ( $\geq 18$ years old) with a BMl of $\geq 40 \mathrm{~kg} / \mathrm{m}^{2}$, or $\geq 35 \mathrm{~kg} / \mathrm{m}^{2}$ with comorbidities. Data on baseline characteristics such as age, sex, baseline weight and BMI were collected, as well as other obesity-related health conditions such as hypertension, type 2 diabetes, GORD, osteoarthritis and depression/anxiety.

\section{Statistical analysis}

The baseline demographic and clinical characteristics were reported as median and interquartile ranges and percentages as appropriate. T-tests were used for univariate baseline characteristics of those with and without $5 \%$ weight loss after engagement with the service. Logistic regression analysis was used to identify independent predictors of $5 \%$ weight loss at 12 months. A cut-off of $5 \%$ weight loss was used as it confers significant improvements in cardiometabolic risk. ${ }^{15}$

\section{Results}

Of the 309 patients initially enrolled, 249 (80.6\%) completed the programme with at least one follow-up. Their baseline health characteristics are shown in Table 1. The median age of the study population was 46 years (IQR 36-55). The participants comprised $66 \%$ females $(n=204)$ and had a median baseline BMI of $44 \mathrm{~kg} / \mathrm{m}^{2}$ (IQR 42-45). Type 2 diabetes was prevalent in 31\% $(n=96)$, hypertension in $35 \%(n=108), G O R D$ in $34 \%(n=106)$ and osteoarthritis in $29 \%$ ( $n=90)$.

The median baseline weight of all 309 participants on enrolment was $126 \mathrm{~kg}$ (IQR 115-138). Throughout the follow-up period of 1 year, the median weight fell to $120.5 \mathrm{~kg}$ at 3 months, $119.6 \mathrm{~kg}$ at 6 months, $117.7 \mathrm{~kg}$ at 9 months and $117.5 \mathrm{~kg}$ at 12 months (Figure 1). The median $\mathrm{HbA}_{1 \mathrm{c}}$ fell from a baseline of $60.25 \mathrm{mmol} / \mathrm{mol}$ to $54.4 \mathrm{mmol} / \mathrm{mol}$ during the follow-up period, as shown in Figure 2. Sixty-four patients had baseline $\mathrm{HbA}_{1 c}$ of $>53 \mathrm{mmol} / \mathrm{mol}\left(7 \% \mathrm{HbA}_{1 \mathrm{c}}\right)$, which fell to $<53 \mathrm{mmol} / \mathrm{mol}$ during the follow-up period in $21 \%$.

Table 2 shows the comparative baseline characteristics of those with and without $\geq 5 \%$ weight loss at the 3 -month followup. $33 \%$ of the study population achieved $5 \%$ weight loss at the end of the 3-month follow-up period. At the end of the initial 3-month follow-up period, older patients $(p=0.0001)$ and those with type 2 diabetes $(p=0.002)$ and dyslipidaemia $(p=0.03)$ were more likely to lose $\geq 5 \%$ weight.

The logistic regression model showed that higher age (OR 
Table 1 Demographic characteristics of 309 severely obese patients enrolled in the Tier 3 weight management service

\begin{tabular}{ll}
\hline & Percentage (n=309) \\
\hline Age, median (IQR) & $46(36-55)$ \\
BMI, baseline median (IQR) & $44(42-45)$ \\
Weight (kg), baseline median (IQR) & $126(115-138)$ \\
Female & $204(66 \%)$ \\
Type 2 diabetes & $96(31 \%)$ \\
Hypertension & $108(35 \%)$ \\
GORD & $106(34 \%)$ \\
Osteoarthritis & $90(29 \%)$ \\
Depression/anxiety & $84(27 \%)$ \\
Dyslipidaemia & $47(15 \%)$ \\
Asthma & $36(11 \%)$ \\
Stress incontinence & $31(10 \%)$ \\
OSA & $27(8 \%)$ \\
PCOS & $21(6 \%)$ \\
Cardiovascular disease & $14(5 \%)$ \\
Pre-diabetes & $13(4 \%)$ \\
NAFLD & $1(0.3 \%)$ \\
BMI, body mass index; GORD, gastro-oesophageal reflux disease; \\
NAFLD, non-alcoholic fatty liver disease; OSA, obstructive sleep apnoea; \\
PCOS, polycystic ovary syndrome.
\end{tabular}

Figure 1. Effect of Tier 3 weight management services on follow-up weight at 3, 6, 9 and 12 months

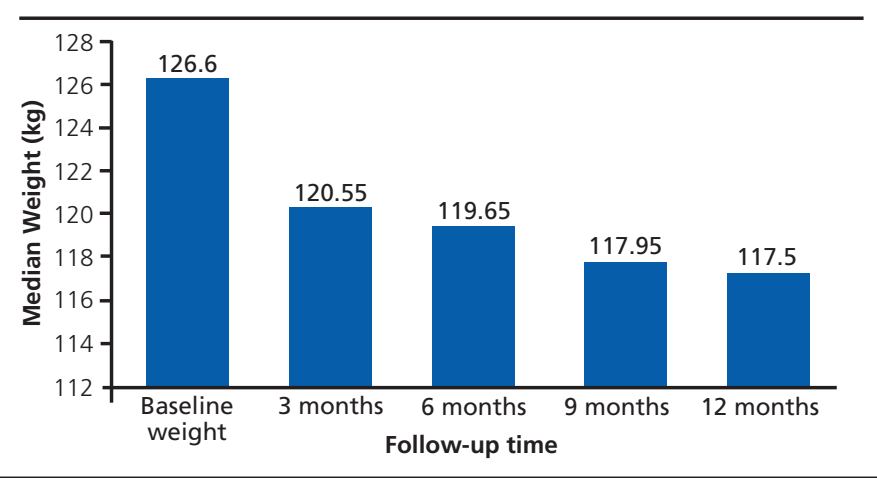

Figure 2. Effect of Tier 3 weight management services on $\mathrm{HbA}_{1 \mathrm{c}}$ in patients with type 2 diabetes during the last follow-up

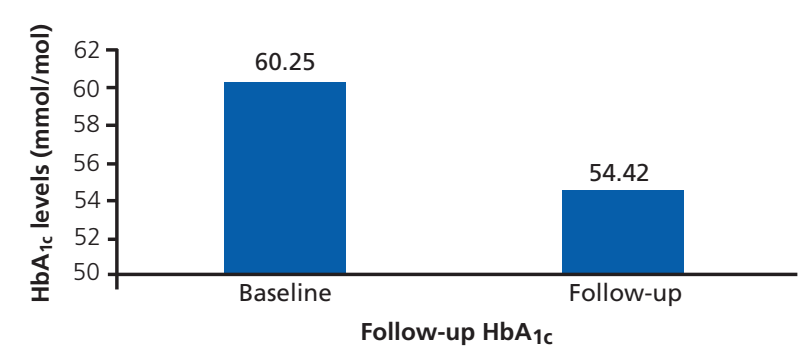

Table 2 Comparative base characteristics of patients with $>5 \%$ weight loss and those with $<5 \%$ weight loss in Tier 3 weight management services

\begin{tabular}{|c|c|c|c|}
\hline & $\begin{array}{l}\geq 5 \% \text { weight } \\
\text { loss }(n=84)\end{array}$ & $\begin{array}{l}<5 \% \text { or no } \\
\text { weight loss } \\
(n=255)\end{array}$ & $P$ value \\
\hline Age, mean & $51(10)$ & $43.5(12)$ & 0.0101 \\
\hline Baseline BMI & $44.5(4.5)$ & $45.4(5.1)$ & 0.15 \\
\hline $\operatorname{Sex}(F)$ & $71(84 \%)$ & $154(68 \%)$ & 0.18 \\
\hline Baseline weight & $124(17.8)$ & $130(21.8)$ & 0.01 \\
\hline Type 2 diabetes & $54(64 \%)$ & $42(18 \%)$ & $<0.0001$ \\
\hline Hypertension & $37(44 \%)$ & $71(31 \%)$ & 0.05 \\
\hline GORD & $30(35 \%)$ & $76(33 \%)$ & 0.85 \\
\hline Osteoarthritis & $28(33 \%)$ & $62(27 \%)$ & 0.39 \\
\hline Depression/anxiety & $23(27 \%)$ & $61(11 \%)$ & 1 \\
\hline Dyslipidaemia & $22(26 \%)$ & $25(11 \%)$ & $<0.0001$ \\
\hline Asthma & $11(13 \%)$ & $25(11 \%)$ & 0.77 \\
\hline Stress incontinence & $10(11 \%)$ & $21(9 \%)$ & 0.8 \\
\hline OSA & $21(25 \%)$ & $6(2 \%)$ & 0.7 \\
\hline PCOS & $1(1 \%)$ & $20(8 \%)$ & NA \\
\hline Cardiovascular disease & $6(7 \%)$ & $8(3 \%)$ & NA \\
\hline
\end{tabular}

Table 3 Predictors of weight loss in Tier 3 weight management services

\begin{tabular}{llll}
\hline & Odds ratio & $\mathbf{9 5 \%} \mathbf{C l}$ & P value \\
Age & 1.05 & 1.02 to 1.08 & 0.0001 \\
Type 2 diabetes & 2.54 & 1.38 to 4.6 & 0.002 \\
Dyslipidaemia & 2.21 & 1.04 to 4.7 & 0.03
\end{tabular}

$1.05, p<0.05)$, type 2 diabetes (OR 2.54, $\mathrm{p}<0.05)$ and dyslipidaemia (OR 2.21, $\mathrm{p}<0.05$ ) were independently associated with more than $5 \%$ weight loss at the 3 -month follow-up (Table 3).

\section{Discussion}

In this study we report the efficacy of Tier 3 weight management services provided by T3WAMS Hull University Teaching Hospitals NHS Trust and identify baseline characteristics associated with weight loss. We have shown that baseline age, diabetes status and presence of dyslipidaemia are independent predictors of weight loss in the Tier 3 programme.

In the present study, 33\% of the participants achieved $\geq 5 \%$ weight loss as recommended by the NICE guidelines, similar to previous studies on T3WAMS. ${ }^{16-20}$ More importantly, maximal weight loss was achieved at 3 months, and most of those with $\geq 5 \%$ weight loss continued to lose weight or maintain the $\geq 5 \%$ weight loss at the end of the 12 months.

This is, to the best of our knowledge, the first study examining the independent predictors of weight loss in T3WAMS. Patients of higher age, those with diabetes and those with dys- 
lipidaemia were more likely to achieve $\geq 5 \%$ weight loss. There are several studies in a non-T3WMS setting which show the beneficial effects of age and diabetes status on weight loss. A study by Crowe et a ${ }^{\beta}$ which looked at an 8 -week structured weight loss programme showed higher rates of completion in older patients, men and those diagnosed with diabetes. They also showed that men and patients with diabetes had an overall greater reduction in waist circumference than non-diabetics and women. Another study in the population from the USA and the UK found a high proportion of obese older adults experienced clinically significant weight loss. ${ }^{21}$

Our study has also shown improvements in glycaemic control following weight loss with T3WAMS. This is consistent with previous studies showing the beneficial effects of weight loss in non-T3WAMS settings. 22,23 T3WAMS can thus be valuable to patients with diabetes, and prompt referral to T3WAMS in those with diabetes and obesity is essential.

Given the cross-sectional nature of the study, we can only speculate why these three factors are likely to be associated with weight loss. It is possible that those with higher age, presence of diabetes and dyslipidaemia were more motivated to lose weight and more likely to engage with the T3WAMS programme. It is also expected that T3WAMS is associated with better control of type 2 diabetes as the patients were promptly initiated on newer oral diabetes medications such as sodiumglucose transport protein 2 inhibitors and glucagon-like peptide1 analogues, which help with weight loss. Similarly, those with dyslipidaemia and other metabolic complications are more likely to be initiated on metformin and weight loss medications such as orlistat, which could not be done in primary care. Since we do not have data on medication prescriptions, we are unable to adjust for these in the regression analysis.

This was a non-randomised longitudinal observation study that represented an active service in clinical practice. Thus, a control was not feasible. Socioeconomic characteristics were not measured, hence the effect of competing priorities such as employment and family circumstances could not be evaluated. Previous observational studies have suggested the impact of patients' socioeconomic status and deprivation scores in their engagement with the Tier 3 service. ${ }^{24}$ Engagement above one follow-up was not assessed, therefore it is not known if higher interaction with the service could be a confounding factor to successful weight loss. Furthermore, the 60 patients who were lost to follow-up or could not complete the study were not further interviewed to discuss the reasons behind the decision. Patients with poor motivation may therefore have been underrepresented. Long-term weight loss beyond one year is unknown, so we could not assess if weight loss was maintained or if low weight loss groups achieved further weight loss after one year. Furthermore, data were collected from patients at various stages of follow-up, so we are not able to make a clear correlation between the number of sessions and outcomes. Finally, our analysis was not adjusted for socioeconomic status deprivation and psychological factors. Further studies are needed to investigate the effect of these factors on the efficacy of T3WMS. Our

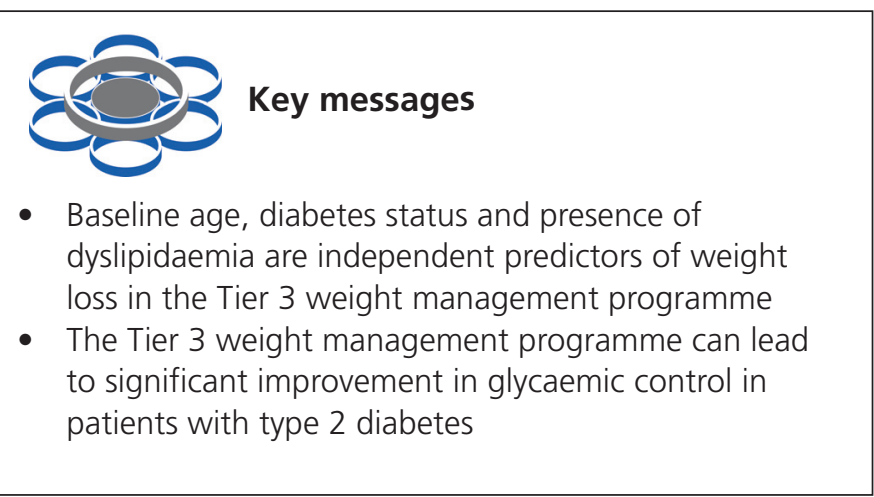

findings were specific to the region covered by the Hull University Teaching Hospitals Trust, an area with a high English Deprivation Index. This may limit the generalisability of the study outcomes to affluent regions in the UK. Larger scale studies are needed to determine whether the results achieved in this paper are generalisable to a broader population.

This study is one of the first to evaluate direct predictors of weight loss in a Tier 3 weight management service. These findings can inform further improvements of this service in deprived regions of the UK where obesity is more prevalent. Additionally, it can provide data on the impact of weight loss on diabetes control, demonstrated by significant decreases in $\mathrm{HbA}_{1}$, which is a current priority across the country. The selection criteria of this study excluded those patients who did not attend follow-ups, minimising the impact of patient motivation on weight loss. The study was conducted in an active clinical setting where the measurement of engagement is not routinely taken; therefore, the results reflect day-to-day challenges faced by this service. Finally, the findings of this study can aid doctors in determining how much weight patients will be expected to lose during their contact with services, improving engagement through realistic and achievable goals.

\section{Conclusion}

This study showed a consistent decrease in weight loss over one year, which also correlated with a reduction in $\mathrm{HbA}_{1 \mathrm{c}}$ in type 2 diabetics. Predictors of weight loss were type 2 diabetes, dyslipidaemia and increasing age. It provides valuable evidence to inform and improve the Tier 3 weight loss services provided by the NHS.

Conflict of interest NS, KL, HD, GIL, ASP, SB have nothing to disclose. KM reports other from Novo Nordisk, other from Lilly, other from NAPP, outside the submitted work. TS reports grants from Novo Nordisk, grants from Abbott, outside the submitted work.

Funding HD is funded by an NIHR clinical lectureship.

\section{References}

1. Alkharaiji M, Anyanwagu U, Donnelly R, Idris I. Tier 3 specialist weight management service and pre-bariatric multicomponent weight management programmes for adults with obesity living in the UK: a systematic review. Endocrinol Diabetes Metab 2019;2(1):e00042. https://doi.org/10.1002/ edm2.42

2. Blane DN, McLoone P, Morrison D, Macdonald S, O'Donnell CA. Patient 
and practice characteristics predicting attendance and completion at a specialist weight management service in the UK: a cross-sectional study. BMJ Open 2017;7(11):e018286. https://doi.org/10.1136/bmjopen-2017018286

3. Brown A, Gouldstone A, Fox E, et al. Description and preliminary results from a structured specialist behavioural weight management group intervention: Specialist Lifestyle Management (SLiM) programme. BMJ Open 2015;5(4):e007217. https://doi.org/10.1136/bmjopen-2014-007217

4. Brown TJ, O'Malley C, Blackshaw J, et al. Exploring the evidence base for Tier 3 weight management interventions for adults: a systematic review. Clin Obes 2017;7(5):260-72. https://doi.org/10.1111/cob.12204

5. Caci G, Albini A, Malerba M, Noonan DM, Pochetti P, Polosa R. COVID-19 and obesity: dangerous liaisons. J Clin Med 2020;9(8). https://doi.org/ 10.3390/jcm9082511

6. Caussy C, Wallet F, Laville M, Disse E. Obesity is associated with severe forms of COVID-19. Obesity (Silver Spring) 2020;28(7):1175. https://doi.org/ 10.1002/oby.22842

7. Ross HM, Laws R, Reckless J, Lean M and Counterweight Project Team. Evaluation of the Counterweight Programme for obesity management in primary care: a starting point for continuous improvement. Br J Gen Pract 2008;58(553):548-54. https://doi.org/10.3399/bjgp08X319710

8. Crowe C, Gibson I, Cunningham K, et al. Effects of an eight-week supervised, structured lifestyle modification programme on anthropometric, metabolic and cardiovascular risk factors in severely obese adults. $B M C$ Endocr Disord 2015;15:37. https://doi.org/10.1186/s12902-015-0038-x

9. Haslam DW, James WP. Obesity. Lancet 2005;366(9492):1197-209. https://doi.org/10.1016/S0140-6736(05)67483-1

10. Homer CV, Tod AM, Thompson AR, Allmark P, Goyder E. Expectations and patients' experiences of obesity prior to bariatric surgery: a qualitative study. BMJ Open 2016;6(2):e009389. https://doi.org/10.1136/bmjopen-2015009389

11. Jackson SE, Beeken RJ, Wardle J. Perceived weight discrimination and changes in weight, waist circumference, and weight status. Obesity (Silver Spring) 2014;22(12):2485-8. https://doi.org/10.1002/oby.20891

12. Lavie CJ, Milani RV, Artham SM, Patel DA, Ventura HO. The obesity paradox, weight loss, and coronary disease. Am J Med 2009;122(12):1106-14. https://doi.org/10.1016/j.amjmed.2009.06.006

13. Lean ME, Leslie WS, Barnes AC, et al. Primary care-led weight management for remission of type 2 diabetes (DiRECT): an open-label, cluster-randomised trial. Lancet 2018;391(10120):541-51. https://doi.org/10.1016/S01406736(17)33102-1
14. Lean MEJ, Leslie WS, Barnes AC, et al. Durability of a primary care-led weight-management intervention for remission of type 2 diabetes: 2-year results of the DiRECT open-label, cluster-randomised trial. Lancet Diabetes Endocrinol 2019;7(5):344-55. https://doi.org/10.1016/S22138587(19)30068-3

15. Logue J, Allardice G, Gillies M, Forde L, Morrison DS. Outcomes of a specialist weight management programme in the UK National Health Service: prospective study of 1838 patients. BMJ Open 2014;4(1):e003747. https://doi.org/10.1136/bmjopen-2013-003747

16. MacLaughlin HL, Hall WL, Condry J, Sanders TA, Macdougall IC. Participation in a structured weight loss program and all-cause mortality and cardiovascular morbidity in obese patients with chronic kidney disease. J Ren Nutr 2015;25(6):472-9. https://doi.org/10.1053/j.jrn.2015.05.001

17. Matsuda M, Shimomura I. Increased oxidative stress in obesity: implications for metabolic syndrome, diabetes, hypertension, dyslipidemia, atherosclerosis, and cancer. Obes Res Clin Pract 2013;7(5):e330-341. https://doi.org/10.1016/j.orcp.2013.05.004

18. Nield L, Kelly S. Outcomes of a community-based weight management programme for morbidly obese populations. J Hum Nutr Diet 2016; 29(6):669-76. https://doi.org/10.1111/jhn.12392

19. Rowe R, Cowx M, Poole C, McEwan P, Morgan C, Walker M. The effects of orlistat in patients with diabetes: improvement in glycaemic control and weight loss. Curr Med Res Opin 2015;21(11):1885-90. https://doi.org/10.1185/030079905X74943

20. Russell GV, Pierce CW, Nunley L. Financial implications of obesity. Orthop Clin North Am 2011;42(1):123-7, vii. https://doi.org/10.1016/j.ocl.2010.09.003

21. Jackson SE, Beeken RJ, Wardel J. Predictors of weight loss in obese older adults: findings from the USA and the UK. Obes Facts 2014;7:102-10. https://doi.org/10.1159/000362196

22. Scheelbeek PFD, Cornelsen L, Marteau TM, Jebb SA, Smith RD. Potential impact on prevalence of obesity in the UK of a $20 \%$ price increase in high sugar snacks: modelling study. BMJ 2019;366:14786. https://doi.org/ 10.1136/bmj. 14786

23. Wing RR, Lang W, Wadden TA, et al. Benefits of modest weight loss in improving cardiovascular risk factors in overweight and obese individuals with type 2 diabetes. Diabetes Care 2011;34(7):1481-6. https://doi.org/ $10.2337 / \mathrm{dc} 10-2415$

24. Wright F, Boyle S, Baxter $\mathrm{K}$, et al. Understanding the relationship between weight loss, emotional well-being and health-related quality of life in patients attending a specialist obesity weight management service. $J$ Health Psycho/ 2013;18(4):574-86. https://doi.org/10.1177/1359105312451865

\section{The effect of dapagliflozin on alanine aminotransferase as a marker of liver inflammation: updated results from the ABCD dapagliflozin audit}

THOMAS SI CRABTREE, MAHENDER YADAGIRI, IAN GALLEN, SUZANNE PHILLIPS, ALISON EVANS, ANURITA ROHILLA, DEVESH SENNIK, ALEX BICKERTON, SUSANNAH ROWLES, ISKANDAR IDRIS, ROBERT E J RYDER, ON BEHALF OF THE ABCD DAPAGLIFLOZIN AUDIT CONTRIBUTORS

(Br J Diabetes 2020;20:19-24 https://doi.org/10.15277/bjd.2020.239)

In the article listed above, one of the co-authors' names had been omitted. Dr Devesh Sennik is now included in the author list and his address details, Consultant \& Clinical Lead Diabetes \& Endocrinology, Princess Alexandra Hospital, Harlow, UK, are included in the author box. The correct version of this can be found online www.bjd-abcd.com/index.php/bjd/article/view/515/747 